\title{
IMPROVISATION IN INFORMATION SYSTEMS DEVELOPMENT
}

\author{
Jørgen P. Bansler \\ Erling C. Havn \\ Technical University of Denmark
}

\begin{abstract}
This paper discusses the role of extemporaneous action and bricolage in designing and implementing information systems in organizations. We report on a longitudinal field study of design and implementation of a Web-based groupware application in a multinational corporation. We adopt a sensemaking perspective to analyze the dynamics of this process and show that improvisational action and bricolage (making do with the materials at hand) played a vital role in the development of the application. Finally, we suggest that this case study provides an occasion to reconsider how we conceptualize information systems development (ISD).
\end{abstract}

Keywords: Web-based groupware, information systems development, sensemaking, improvisation, bricolage

\section{INTRODUCTION}

IS researchers have studied the process of developing and implementing information systems for a long time and a substantial body of research now offers insights into the problems and issues associated with the design and implementation of information systems in organizations. Much of this research, however, embodies assumptions about agency, knowledge, organizational change, and technological innovation that are misleading and inappropriate given the situated and emergent nature of organizational IS development (Gasson 1999; Truex et al. 1999). Information systems are no longer stable, discrete entities, but part of elaborate networks and information infrastructures that are subject to constant adjustment and adaptation (Ciborra et al. 2000).

Mainstream research is premised on the belief that information systems development (ISD) in organizations is a planned, deliberate activity—bounded in time 
and carried out in a systematic and orderly way. ${ }^{1}$ ISD is commonly viewed as a rational design process, organized in formal projects with a clear purpose and a well-defined beginning and end. Another fundamental assumption is that ISD is a methodical process (Truex et al. 2000), that is, a managed, controlled activity performed in adherence to the principles and rules of a systems development method. The concept of method dominates the current discourse about ISD to such a degree and "has been so strongly impressed on our thinking about systems development, that the two concepts, information systems development and information systems development method, are completely merged in systems development literature" (Truex et al. 2000, p. 56). This privileged position of the method concept in the discourse on systems development inhibits our understanding of how information systems are developed in practice. As Truex et al. (2000, p. 74) emphasized, "When the idea of method frames all of our perceptions about systems development, then it becomes very difficult to grasp its non-methodical aspects." When adherence to methods is taken for granted, activities and situations that do not fit within a methodical frame become marginalized and practically invisible, e.g., how ISD is subject to fortuity, circumstance, human whims, talents, and the personal goals of the managers, designers, and users involved.

The objective of this paper is, then, to develop an alternative perspective on ISD-a perspective that posits improvisation and emergent change rather than methodical behavior and planned change as fundamental aspects of ISD in organizations. We recognize, of course, that ISD can be and often is performed as a deliberate, purposeful project with formal governance structures, requirement specifications, milestones, and substantial technological and organizational resources. However, we want to highlight the fact that ISD also happens in a myriad of other ways and that important activities take place outside of the formal projects-in the cracks and crevices in the official project portfolio so to speak. These development processes are more emergent, more continuous, more filled with surprise, more difficult to control, more tied to their circumstances and more affected by what people pay attention to than by intentions, plans, and methodologies (Weick 1993b). They are grounded in the situated practices of organizational actors, and emerge out of their experience with the everyday contingencies, breakdowns, exceptions, opportunities, and unintended consequences that they encounter when they appropriate, adapt, and experiment with new technologies in their work (Orlikowski 1996).

We ground our argument on the findings from a longitudinal case study of the development of a Web-based groupware system in a large multinational corporation. The findings from the case study show that improvisation, emergent change, and unanticipated outcomes may play a vital role in ISD, and that the development of IS in organizations may depend on serendipity and chance to a much higher degree than we usually want to admit.

\footnotetext{
${ }^{1}$ Alternative, less rationalistic perspectives do, of course, exist, even though they still tend to be rather marginalized in the scientific discourse on ISD. Good examples of these less rationalistic perspectives include the body of work on reflective systems development (Andersen et al. 1990; Mathiassen 1998), which has its root in Scandinavia, and the stream of new, agile software development approaches (Cockburn 2002; Highsmith 2002), which recently has attracted enormous interest from academics as well as practitioners.
} 


\section{IMPROVISATION IN ORGANIZATIONS}

It is only relatively recently that organizational researchers have become interested in improvisation, but a growing number of researchers are now starting to take an interest in improvisational action and its potential value to organizations. A prominent group of scholars have used jazz and improvisational theater as a metaphor to develop their theoretical ideas about extemporaneous action in organizations (e.g., Barrett 1998; Hatch 1997, 1998, 1999; Mirvis 1998; Peplowski 1998; Weick 1993b, 1998). Others have drawn on anecdotal and empirical evidence to study organizational improvisation more directly. For instance, researchers have analyzed improvisation in new product development (Eisenhardt and Tabrizi 1995; Miner et al. 2001; Moorman and Miner 1998a, 1998b), strategy formulation and implementation (Perry 1991, 1994), implementation of new technologies (Orlikowski 1996), and during emergencies such as a failed navigational system (Hutchins 1991), an earthquake (Lanzara 1983), and a firestorm (Weick 1993a).

A working definition of improvisation can be taken from jazz music, where it connotes composing and performing contemporaneously (Barrett 1998; Weick 1998). Within organizations, it can be described as the conception of action as it unfolds, drawing on available material, cognitive, affective, and social resources (Cunha et al. 1999). It means that

(1) Improvisation is deliberate, meaning that it is the result of intentional efforts on the behalf of the organization and/or any of its members.

(2) Improvisation is extemporaneous. It deals with the unforeseen; it works without a prior plan and without blueprints and methods (Weick 1993b).

(3) Improvisation occurs during action, meaning that organizational members do not stop to analyze a perceived problem or an unanticipated opportunity and come up with a plan. Instead they develop their response by acting on the problem or opportunity, and can only judge its suitability by hindsight, not by foresight as in traditional planning (Cunha et al. 1999).

(4) Improvisation implies the preexistence of a set of resources, be it a plan of action, tools and technologies, knowledge, or a social structure, upon which variations can be built (Cunha et al. 1999; Weick 1998).

Most authors agree that organizational improvisation can happen in varying degrees, i.e., it occurs along a continuum ranging from spur-of-the-moment action to entirely planned action (Cunha et al. 1999; Moorman and Miner 1998a, 1998b).

Organizational improvisation is closely linked to the concept of bricolage, i.e., the ability to use whatever resources and repertoire one has to perform whatever task one faces (Lanzara 1999; Louridas 1999; Weick 1993b). Because improvisation means to act in an extemporaneous and spontaneous way to changing needs and conditions, improvisers cannot wait for optimal resources to be deployed and have to tackle the issues at hand with currently available resources (Cunha et al. 1999; Weick 1993b, 1998). Therefore, when improvisation happens, then necessarily, bricolage will too.

The increased interest within organizational studies in improvisation provides some conceptual grounding for the study of improvisation and bricolage in IS development. 
In the research study described below, we explore the development of a Web-based groupware system intended to support globally dispersed, product development work of a large and highly successful multinational organization (BioCorp).

\section{RESEARCH SETTING AND METHOD}

BioCorp is a multinational biotechnological company that manufactures a range of pharmaceutical products and services. BioCorp's headquarters are in Northern Europe, but the corporation has production facilities, research centers, and sales offices in 68 countries. In 2001, BioCorp employed more than 16,000 people and the net turnover was $\$ 2.8$ billion. During our field study, the corporate IT department was turned into a separate (limited liability) company. We include this information because this change had a significant impact on the relations between IT staff and users in our case.

The groupware system we studied was developed in-house, as a collaborative effort between people in the Project Management Unit within BioCorp's R\&D division and the corporate IT department. The purpose of the system was (or rather turned out to be) to support communication and collaboration among participants in the company's drug development projects.

These projects are complex, large-scale, long-term endeavors. A typical project lasts 9 to 10 years and involves up to 500 people from many different areas within the company (e.g., clinical research, engineering, marketing, and regulatory affairs). Most of the activities are carried out at sites in Scandinavia and Northern Europe, but clinical trials are conducted in the United States, Singapore, Japan, and a number of other countries worldwide. The fact that a growing number of BioCorp's new drugs are developed in close collaboration with external partners in Japan, the United States, and Europe further adds to the distributed and complex nature of the projects.

The Project Management Unit (PMU), located at headquarters, is responsible for managing the development process and for ensuring efficient coordination of all the tasks and resources involved in a development project. It combines the skills of a large number of units working in matrix organization set-ups. PMU includes a number of project directors, each of whom is responsible for the management of a selected number of cross-functional drug development projects. Each project director has a personal assistant who acts as his/her "right hand." In addition, every project is headed by a group of middle managers - the so-called core group — coming from different functional areas.

Although formal as well as informal face-to-face meetings are central to communication and sensemaking within the projects, the dispersed nature of the organization means that project members must also rely heavily on a variety of communication technologies to facilitate various modes of work. At the time of our study these included familiar technologies such as mail, telephone, and fax but also more advanced technologies such as ftp, shared LAN drives, e-mail, video conferencing, and electronic calendars.

\section{DATA COLLECTION AND ANALYSIS}

Previous empirical studies of ISD (e.g., Bansler and Bødker 1993; Fitzgerald 1998; Gasson 1999) have focused on system development methods and how they are applied 
in formal projects. Rather than starting from the assumption that formal projects and methods play a key role in ISD, we wanted to observe how the development of an information system actually unfolded in a large, complex organization and track events and activities over a prolonged period of time. We wanted to focus on events in their natural setting and capture the rich array of subjective experiences of organization members during the development process.

Consistent with the focus of our research, we followed an interpretive case study approach (Myers 1997; Stake 2000, Walsham 1993). Interpretive field research is particularly appropriate for understanding human thought and action in natural organizational settings (Klein and Myers 1999). This approach allowed us to gain insights into the processes related to the development, implementation, and use of the groupware system and, in particular, to examine how different actors' technological frames and organizational priorities changed over time as they interacted with the technology. This enabled us to throw light upon the critical role of bricolage and improvisation. Moreover, this approach is also useful for discovering new insights when little is known about a phenomenon. It allows for casting a new light on complex processes whose structure, dimensions, and character are yet to be completely understood (Myers 1997).

Our field data collection lasted for more than three years and we used several data sources and modes of inquiry (for triangulation). The two primary data collection methods used were interviews and examination of archival data, but we also participated in a number of formal and informal meetings with developers and users. Finally, we examined different versions of the software under development.

Interviews. We began interviewing managers and employees of BioCorp in August 1998 and concluded the last interview three years later, in September 2001. During this period, we conducted 34 qualitative interviews of 60 to 120 minutes in length. All interviews were recorded and transcribed. Participants represented a diverse array of occupations and organizational positions, and included project directors and project assistants from PMU, members of several large development projects, as well as managers, analysts, and programmers from the corporate IT department. We interviewed developers and users throughout the research process. The goal of these ongoing interviews was to gather information about important events and actions and to track changes in the way people experienced the technology and perceived the new communicative affordances provided by it. We also wished to avoid such problems as poor recall, hindsight bias, and rationalizations.

Archival data. We reviewed public materials such as annual reports and company brochures as well as internal documents such as the company newsletter, organization charts, the corporate IT strategy, the IT project model, the project manual concerning the discovery and development of new medicinal drugs, the guidelines for organization and management of development projects, and the set of user manuals for the groupware system. This provided general information on company history, structure, core competencies, culture, IT policies, IT infrastructures, and IT expertise, as well as more specific data on the organization and management of the medicinal drug development projects (including formal planning and project management models), and the groupware system itself. 
Meetings and informal conversations. We held two meetings with the director of PMU and several meetings with the IT manager responsible for the groupware system. We also participated in a one-day workshop with users and developers in spring 2001. The purpose of the workshop was to discuss user requirements for the next version of the groupware system. In addition to the formal meetings, we had many informal conversations with users and developers during our visits to the company and on the phone in connection with meetings or interviews.

Examination of the application. We had the opportunity to inspect the different versions of the groupware system on several occasions. In addition, when interviewing users, we often asked them to demonstrate how they used the system and show us the content of the document base. In this way, we gained first-hand knowledge about the system and its salient features.

We used qualitative techniques to analyze the data, informed by the overall focus on sensemaking, improvisation, and bricolage. We analyzed all data sources in a process of recursive scrutiny to get as complete a picture as possible of the design, implementation, and use of the groupware system. This process was "not unlike putting the pieces of a puzzle together, except that the pieces are not all given but have to be partially fashioned and adjusted to each other" (Klein and Myers 1999, p. 79). We endeavored to place our findings in the context of relevant literature and in interpreting our data we constantly referred to relevant bodies of research on improvisation, sensemaking, information systems development, and so on. Thus, the processes of reporting the findings and conducting the analysis were highly connected and interwoven.

We shared our preliminary findings with key informants in PMU and the IT department, and they provided helpful comments that confirmed and elaborated the identified issues and conclusions drawn. By discussing our findings with the key informants, we explicitly recognize that the participants in the study-just as much as the researchers - are interpreters and analysts and that the story we tell is a result of our interaction with the participants (Klein and Myers 1999).

\section{CASE STUDY}

In what follows, we examine the development and use of the groupware system in PMU_from fall 1998 when the idea was first conceived by people in PMU until fall 2001 when the third version of the application had been in use for more than a year. Three versions of the application were developed during this three-year period.

The first version was developed by a couple of entrepreneurial people in PMU and was simply a modified piece of software that they had borrowed from BioCorp's library. It turned out to be virtually useless in practice, but it generated enough enthusiasm and inspiration to continue the development process.

The second version, named ProjectWeb, was developed in close collaboration with a couple of programmers from the corporate IT department. This version was well received by the intended users and the PMU management decided to make use of the system mandatory for all drug development projects.

The development of the third version was a very different story. By that time, the corporate IT department had been transformed to an independent company within the 
BioCorp group and saw an interest in turning ProjectWeb into a generic application, which they could market broadly within—as well as outside—BioCorp. Thus, the primary driving force behind the third version was not PMU, but the IT department.

We now discuss the development and use of each version in detail, focusing on the fragmented, ambivalent, and capricious nature of the process.

\subsection{Version 1}

A small group of entrepreneurial people at PMU—in particular a visionary project director (Carl), his enterprising assistant (Stella) and the so-called IT supporter (Jean, a self-taught IT specialist who assisted PMU's computer users in countless ways) - were the prime movers in the development of the first version of ProjectWeb. It is difficult to pinpoint exactly when the idea of building a Web-based groupware system came into existence and who the originator was but, according to Stella, the first time the idea of using Web-technology to improve project communication was discussed was in 1997.

It started at the annual PMU departmental seminar, where Carl [project director] called for a PMU-Web. Confidentially, the former manager was no technical wizard, and all the others hadn't given it much consideration. So, it was a discussion between the two: Carl, who was all for it, and the former manager who was against [it].

It was not until a year later, in 1998 (and after the appointment of a new PMU manager), that they first attempted to exploit the new technological opportunities. The project directors (and the new PMU manager) agreed that all projects should create a Web site to facilitate internal project communication. The task of creating and maintaining these new Web sites was assigned to the project assistants and Microsoft FrontPage was chosen as the common tool. However, it soon turned out that FrontPage was totally inadequate for the job at hand.

Jean, the IT supporter, concluded that the project assistants needed a better tool—a tool that was more advanced than FrontPage in terms of facilities, but at the same time easy to use. She contacted a Web-savvy person she knew in the corporate IT department who told her that the corporate library had similar ideas and that they had created a piece of software, which might be useful. Jean acquired the program from the library and made a few modifications to it before she let two project assistants, including Stella, test it. The result was, however, disappointing, the program was too primitive and much too difficult to use.

They had tasted blood, however, and decided that the next step would be to develop a better tool themselves.

\subsection{Version 2}

Jean realized that she did not possess the necessary programming skills to develop a better tool on her own and that the corporate IT department had to be involved in the process. Together with Stella and the project director Carl, she persuaded the new PMU manager to fund the project. 
Development. The development of version 2 took place in close collaboration between Jean and Stella from PMU and two people from the IT department, a programmer (David) and a graphics designer (Hal). It was, however, according to David, the users who had the initiative and set the course.

Version 2 grew out of what they [the users] came with as input. Stella has been the one giving the most input. She was also one of the main users, a very active user. That's how there was a lot of input to what new things could be done.

They took version 1 as their starting point and added new ideas along the way. It was not a formal or systematic process, but rather a process relying on informal conversations, free exchange of ideas, and extensive use of prototypes.

I am not sure that there is any formalized [documentation]. I don't think so. Most of it was working papers. It was enough with my prioritized listings, when there is only one guy developing it. We haven't worked according to our quality department's goals and specifications. It's been based on prototyping and on close cooperation with the customer.

It is important to understand that in the beginning neither Jean nor Stella had a clear idea of what kind of system or tool they were about to design. Jean, for instance, explained that her initial idea had been that ProjectWeb should be a tool to facilitate file sharing in distributed groups. She saw ProjectWeb as an alternative to the common LAN drives, which some of the projects at that time used to share documents. In her opinion, LAN drives were not a good solution. They were difficult to manage and required too much insight into technical matters (e.g., security measures).

Stella, on the other hand, saw ProjectWeb as an alternative to e-mail. She was enthusiastic about what Web technology could offer in presenting information in a much more interesting, clear, and visually attractive way-e.g., by using different colors, fonts, graphic effects, links, and pictures. "ProjectWeb is a graphic version of e-mail," she said. She continued, "ProjectWeb is the greatest revolution since the e-mail. You can communicate in a much better way. It's more graphical, and you have a kind of library that includes all the information."

In summary, Jean and Stella had some vague ideas of how Web technology could be leveraged to improve project communication, but they did not know exactly what they wanted at the outset of the design process. It was only during the design process, through their interactions with David and Hal and through their joint exploration of different solutions (prototypes) that it gradually became clear what the tool should do and how it should be designed.

Implementation and use. Version 2 was finished and ready for launch in April 1999. PMU management decided that all development projects should establish an internal web site using ProjectWeb, but refrained from laying down guidelines for the design, content, or use of these Web sites. As a consequence, each project director and his or her assistant had to figure out for themselves how to use the application and for what purposes. They were, of course, uncertain about what to do, and the result was that ProjectWeb use varied significantly from one project to another. One of the directors 
explained that they did not really know what they were able to do with the new technology, and that they had to "experiment a little with the medium" to explore its advantages and limitations.

The problem is, I'm not an IT nerd, and I'm not familiar with what possibilities the media has. And that's why it is about feeling your way as you go. I don't have any clear IT strategy for my project, and it may suffer as a result, if you look at it as a specialist. But we're in a process where we have to figure out what the media has to offer, and then we'll be able to get the best out of it.

At this point in time, the technology did not have a fixed or common meaning. Some directors, for instance, were mostly occupied with the problems of managing the huge amount of reports, letters, clinical data, and other records, which are produced during the lifetime of a project and have to be kept for future reference. From their perspective, ProjectWeb was an electronic document management system. Others were more focused on effective communication and team building and primarily considered ProjectWeb as a new medium of communication.

It [ProjectWeb] is a fantastic communication tool for a multinational project group, where we don't know much about, how shall I say it, our customers and colleagues in the project. It offers the possibility of conveying information immediately. It offers a place where people can see everything that's relevant to the project, who's involved in the project, who's responsible, etc.

After having used and experimented with ProjectWeb for some time, the most active users started to come up with ideas and suggestions for improvements and additions to the system. The three most important suggestions were

(1) Many project assistants pointed out that needs and requirements varied from one project to another and they consequently wanted the system to be more flexible and easier to customize.

(2) Some of the project directors wanted the ability to restrict access to confidential or sensitive information. For instance, they would like the core group to have their own private space on the project's Web site.

(3) The directors of joint projects with external partners wanted to be able to open up their Web sites to allow external collaborators access to (at least some of) the material on the project's Web site.

\subsection{Version 3}

The development of version 3 started up shortly after the release of version 2. It was released in spring 2000 and was still in use when we finished our field study in the fall of 2001.

Development. The development of version 3 differed from the development of the previous versions in one important way. The IT department had taken over the initiative 
and managed to position itself as the leader and driving force. They considered ProjectWeb as a potential "cash cow" and believed that if they could turn it into a generic software product, marketable to other business units in BioCorp and even to other companies, then they would be able to make a substantial profit. As one of the project manager in the IT department explained,

we thought about it. The [application] was probably something that many... could use. So, we thought that if we could make a small generic [software] package, then we could probably earn a lot ofmoney. And that's what we want. So, we continued to make it as a small package, just like when you buy a small software package, just like when you buy [Microsoft] Word.

One consequence of this shift in direction and leadership was that PMU's influence was reduced and, more generally, that the communication between the users and the developers became less spontaneous and direct.

Furthermore, the development of version 3 entailed a shift to a new technical platform. Whereas versions 1 and 2 had been implemented by means of ASP (active server pages) technology, version 3 was constructed as an assembly of objects programmed in Visual Basic. The purpose was to obtain a more robust and reliable solution, which would scale up and accommodate large numbers of users without problems. This objective was obviously bound up with the wish to create a marketable, generic product.

Version 3 also included a number of new facilities.

(1) Facilities to change the look and feel of the user interface (e.g., the color scheme) and customize menus and toolbars

(2) Facilities to manage authorization and access control to confidential or sensitive material

(3) Facilities to create and manage project Web sites with external partners (e.g., facilities to handle security and privacy issues)

Judging from this, it is our impression that the wishes of Stella, Jean, and the other users from PMU were accommodated even though they felt they had been shunted out of the development process.

Implementation and use. In general, the project directors and assistants in PMU were excited about the many new features and began immediately to explore the new facilities in various ways. Some projects continued to treat ProjectWeb as a broadcast medium and focused on how to exploit the new facilities to create more interesting content, for instance by adding more pictures and better graphics.

Other projects were more interested in the new facilities to restrict access to sensitive information and began to explore how ProjectWeb could be used to create private work spaces and in that way support knowledge sharing and collaboration in smaller work groups. As an alternative to distributing work group documents and drafts as email attachments, they started to store them in private workspaces on the project's Web site. In other words, they began to use Project Web to support small-group collaboration-something for which the application was not initially designed. The ability to 
restrict access to documents was essential to this new practice because work groups did not want to share private documents and unfinished drafts with outsiders.

As a final remark, we would like to add that, within BioCorp, version 3 of ProjectWeb is regarded as a highly successful Web application. More than 70 large projects with hundreds of participants each currently use the system and development of the next version (number 4) has already begun.

\section{DISCUSSION}

The case of ProjectWeb shows that important, innovative IS development activities may take place outside of formal ISD projects-as creative organizational actors learn about new technological opportunities, modify systems to match emergent organizational requirements, experiment with local innovations, respond to unanticipated problems, or adapt existent technologies to new uses. These activities (which may be labeled innovation "in the small") are less manifest and more difficult to grasp than formal development projects with steering committees, project managers, milestones and fixed budgets (innovation "in the large") but, we would argue, equally important.

The case also demonstrates that users may be an important source of innovation. Unlike most managers (and IT specialists), they have detailed, first-hand knowledge of how work is actually done and they personally experience the frustrations, troubles, and breakdowns caused by inexpedient work procedures, rigid rules, and inadequate or outdated technologies. As a consequence, they are often both motivated and able to come up with creative solutions to recurring problems and discover opportunities to improve their work practices by exploiting new technologies.

Three aspects of the ProjectWeb development process are thrown into relief when we contrast it with the way ISD is usually portrayed in IS research.

Sensemaking. It is striking how little the key designers of ProjectWeb (Stella and Jean) knew about what they were doing at the beginning of the development process. They did not have a clear goal or a precise idea about what they were designing or how it would fit into people's work practices. On the contrary, it was difficult for them to make sense of the Web technology and their first attempts to conceptualize the emerging system relied on comparisons with older, more familiar technologies (LAN drives and e-mail). It was not until they started experimenting with the design that they began to develop more detailed and sophisticated technological frames (Orlikowski and Gash 1994) and mental models of the technology. It was then they discovered what they wanted to do with it. Their understanding of the technology and their design goals evolved gradually and interactively as they developed new versions of the system in close collaboration with David and Hal (from the IT department) and tested it in practice together with their fellow users in PMU.

The point we want to make is that the development of ProjectWeb was fundamentally a sensemaking process (Weick 1995). Sensemaking is a process where people strive to convert a world of experience into an intelligible and meaningful world. It "is about sizing up a situation, about trying to discover what you have while you simultaneously act and have some effect on what you discover" (Weick 1999). It is an attempt to grasp a developing situation - in this case, the design and implementation of an inno- 
vative information system-in which the observer affects the trajectory of that development. Because new technologies are equivocal and thus lend themselves to multiple, conflicting interpretations, all of which are plausible, the development and use of technical systems require ongoing sensemaking (Weick 1990).

At the heart of sensemaking is the idea that understanding lies in the path of action. Action precedes understanding and focuses interpretation. It was by developing prototypes and trying out different versions of ProjectWeb in practice that Stella and Jean (and David and Hal) began to discover what their emergent system design meant and where they were heading. This is an example of "sense-making as manipulation" (Weick 1995). Sensemaking by means of manipulation involves acting in ways that create something (e.g., a new technology in use) that people can then comprehend and manage.

Manipulation generates clearer outcomes in a puzzling world, and these outcomes make it easier to grasp what might be going on. Manipulation is an operationalization of the advice, "leap before you look" or the advice, "ready, fire, aim." Manipulation is about making things happen, so that a person can then pounce on those created things and try to explain them as a way to get a better sense of what is happening (Weick 1995 p. 168).

The key point is that sensemaking is an active process and that action is a precondition for sensemaking: "Action is intelligence, and until it is deployed, meaning and sense will be underdeveloped" (Weick 1993c).

Improvisation. The development of ProjectWeb was not guided by a preconceived plan or a systematic method. On the contrary, it was informed by hunches rather than well-developed knowledge, it relied on ad hoc solutions, and it had a strong core of experimentation and unjustified trial and error. In other words, the actors (users as well as developers) depended on improvisation and extemporaneous action in order to cope with unexpected problems, unanticipated opportunities, multiple meanings, and transient organizational requirements.

Improvisation deals with the unforeseen; it works without a prior plan and without blueprints and methods (Weick 1993b). "Improvisation is the deliberate and substantive fusion of the design and execution of a novel production" or performance (Miner et al. 2001, p. 314). It can be conceived of as a form of short-term learning where real-time experience informs novel action at the same time that the action is being taken. Much research on improvisation has focused on individuals, but improvisational action can occur at any level (individual, team, organization) and is often a collective process (Miner et al. 2001), as when Jean, Stella, David, and Hal together designed the second version of ProjectWeb.

The notion of improvisation implies that attention and interpretation rather than intention and decision making drives the process of designing. From this perspective, ISD is more an act of interpretation rather than an act of decision-making. The people involved improvise to make sense of unexpected possibilities and constraints that emerge. They are never in full control of the development process, but continuously challenged by having to address the unintended effects that are so commonplace in development projects. As a consequence, people are forced to revise their sense of what 
is happening and what can be accomplished. These revised interpretations are what guide action, not the initial decisions (Weick 1993b). Since the only things we can sense are enacted events that have already taken place, attention rather than intention becomes central to the design process.

Bricolage. The development of ProjectWeb was clearly a process that made do with whatever materials were at hand. Version 1, for instance, was a modified version of a program that Jean borrowed from the corporate library and important important elements of version 1 were again reused in version 2. Thus, ProjectWeb is a good example of the general phenomenon that "new systems are built, sometimes literally, on the ruins and with the ruins of old systems" (Lanzara 1999, p. 346). Pieces of past code become building materials and are used, together with available commercial software components (in this case a Web server and a DBMS from Microsoft), to construct new systems, which then become more or less coherent assemblies of mixed components.

In other words, the development of ProjectWeb can best be described as an instance of bricolage, i.e., a constructive activity based on transforming and reshaping what is already in use, or creatively rearranging components to fulfill new purposes (Lanzara 1999). The French word bricolage means "to use whatever resources and repertoire one has to perform whatever task one faces" (Weick 1993b). Invariably the resources are heterogeneous and less well-suited to the exact project than one would prefer but they are all there is. The materials are not project-specific, but, instead, they represent the contingent result of all of the previous uses to which those items have been put. The key to understanding the nature of bricolage as an innovative activity is Levi-Strauss' statement that materials "are not known as a result of their usefulness; they are deemed to be useful or interesting because they are first of all known" (Levi-Strauss 1966, cited in Weick 1993b).

Bricolage is closely associated with improvisation. Improvisation increases the chances that bricolage will occur because there is less time to obtain the necessary materials and resources in advance. Bricolage and improvisation are not synonymous, however, as bricolage (at least in theory) can occur in nonimprovisational contexts (Miner et al. 2001).

In summary, the development process we have described and analyzed here differs remarkably from the orderly, structured paths that most current IS theories and methods tend to assume. Instead, we have observed a more emergent, more spontaneous, more open-ended, and more continuous process involving bricolage, unjustified trial and error, small-scale practical experiments, local readjustments, and improvisations. The process has been shaped more by action than by plans, and more by attention than by intention.

As already mentioned in the introduction, we realize that this study is exploratory, that ProjectWeb belongs to a special class of information systems, and that this fact may limit the generality of our findings. Consequently, future research should engage in careful testing of our concepts and relationships in other ISD contexts.

\section{CONCLUSION}

The case ofProjectWeb provides an occasion to think more carefully about the way we conceptualize ISD. We believe it is about time to dismiss the tradition of viewing 
ISD as an inherently rational, methodical, and orderly process. System development processes, in our experience, are never very tidy, neat, or sensible, and the importance and value of system development methods in practice are vastly overestimated (Bansler and Bødker 1993; Ciborra 1998; Fitzgerald 1998; Gasson 1999; Truex et al. 2000). System developers and users find themselves in a more complex, less stable, and less well-understood world than assumed by most IS researchers. They are placed in a world that does not always make sense and over which they often have only modest control.

Thus, there is a pressing need to develop an alternative theoretical perspective on ISD-a perspective that takes the messy reality of systems development practice seriously and makes it possible to grasp its non-methodical, unplanned, and fortuitous aspects. We believe that the concepts of sensemaking, improvisation, and bricolage proposed here constitute a useful starting point for developing such a perspective. They offer a theoretical lens for examining how people cope with ISD in practice and explaining why methods and plans have limited value in most real-life situations.

\section{ACKNOWLEDGMENTS}

We are grateful to the members of BioCorp who participated in this research. We also thank Hanne W. Nicolajsen, Dixi L. Henriksen, and Jens K. Pors for their assistance in the fieldwork. This study was supported in part by a grant from the Danish Research Councils (grant no. 99-00-092).

\section{REFERENCES}

Andersen, N. E.; Kensing, F.; Lassen, M.; Lundin, J.; Mathiassen, L.; Munk-Madsen, A.; and Sørgaard, P. Professional System Development, Englewood Cliffs, NJ: Prentice-Hall, 1990.

Bansler, J. P., and Bødker, K. "A Reappraisal of Structured Analysis: Design in an Organizational Context," ACM Transactions on Information Systems (11:2), 1993, pp. 165-193.

Barrett, F. J. "Coda: Creativity and Improvisation in Organizations: Implications for Organizational Learning," Organization Science (9:5), 1998, pp. 558-560.

Ciborra, C. U. "Crisis and Foundations: An Inquiry into the Nature and Limits of Models and Methods in the Information Systems Discipline," Journal of Strategic Information Systems (7), 1998, pp. 5-16.

Ciborra, C. U.; Braa, K.; Cordelia, A.; Dahlbom, B.; Failla, A.; Hanseth, O.; Hepsø, V.; Ljungberg, J.; Monteiro, E.; and Simon, K. A. From Control to Drift., Oxford: Oxford University Press, 2000.

Cockburn, A. Agile Software Development, Boston: Addison-Wesley, 2002.

Cunha, M. P.; Cunha, J. V.; and Kamoche, K. "Organizational Improvisation: What, When, How and Why," International Journal of Management Reviews (1:3), 1999, pp. 299-341.

Eisenhardt, K. M., and Tabrizi, B. N. "Accelerating Adaptative Processes: Product Innovation in the Global Computer Industry," Administrative Science Quarterly (40), 1995, pp. 84-110.

Fitzgerald, B. "An Empirical Investigation into the Adoption of Systems Development Methodologies," Information \& Management (34), 1998, pp. 317-328.

Gasson, S. "A Social Action Model of Situated Information Systems Design," The DATA BASE for Advances in Information Systems (30:2), 1999, pp. 82-97.

Hatch, M. J. "Exploring the Empty Spaces of Organizing: How Improvisational Jazz Helps Redescribe Organizational Structure,” Organization Studies (20:1), 1999, pp. 75-100. 
Hatch, M. J. "Jazzing Up the Theory of Organizational Improvisation," Advances in Strategic Management (14), 1997, pp. 181-191.

Hatch, M. J. "The Vancouver Academy of Management Jazz Symposium: Jazz as a Metaphor for Organizing in the $21^{\text {st }}$ Century," Organization Science (9:5), 1998, pp. 556-568.

Highsmith, J. Agile Software Development Ecosystems, Boston: Addison-Wesley, 2002.

Hutchins, E. "Organizing Work by Adaptation," Organization Science (2:1), 1991, pp. 14-39.

Klein, H. K., and Myers, M. D. "A Set of Principles for Conducting and Evaluating Interpretive Field Studies in Information Systems," MIS Quarterly (23:1), 1999, pp. 67-94.

Lanzara, G. F. "Between Transient Constructs and Persistent Structures: Designing Systems in Action," Journal of Strategic Information Systems (8), 1999, pp. 331-349.

Lanzara, O. F. "Ephemeral Organizations in Extreme Environments: Emergence, Strategy, Extinction," Journal of Management Studies (20), 1983, pp. 71 -95.

Louridas, P. "Design as Bricolage: Anthropology Meets Design Thinking," Design Studies (20:6), 1999, pp. 517-535.

Mathiassen, L. "Reflective Systems Development," Scandinavian Journal of Information Systems (10:1/2), 1998, pp. 67-118.

Miner, A. S.; Bassoff, P.; and Moorman, C. "Organizational Improvisation and Learning: A Field Study," Administrative Science Quarterly (46), 2001, pp. 304-337.

Mirvis, P. H. "Variations on a Theme: Practice Improvisation," Organization Science (9:5), 1998, pp. 586-592.

Moorman, C., and Miner, A. "The Convergence Between Planning and Execution: Improvisation in New Product Development," Journal of Marketing (62), 1998a, pp. 1-20.

Moorman, C., and Miner, A. "Organizational Improvisation and Organizational Memory," Academy of Management Review (23:4), 1998b, pp. 698-723.

Myers, M. D. "Qualitative Research in Information Systems," MISQ Discovery, 1997.

Orlikowski, W.J. "Improvising Organizational Transformation over Time: A Situated Change Perspective," Information Systems Research (7:1), 1996, pp. 63-92.

Orlikowski, W. J., and Gash, D. C. "Technological Frames: Making Sense of Information Technology in Organizations," ACMTransactions on Information Systems (12:2), 1994, pp. 174-207.

Peplowski.K. "The Process of Improvisation,” Organization Science (9:5), 1998, pp. 560-561.

Perry, L. T, "Real Time Strategy: Improvising Team Based Planning for a Fast Changing World," Organizational Dynamics (22), 1994, pp. 76-77.

Perry, L.T. "Strategic Improvising: How to Formulate and Implement Competitive Sstrategies in Concert," Organizational Dynamics (19:4), 1991, pp. 51-64.

Stake, R. E. "Case Studies," in N. K. Denzin and Y. S. Lincoln (Eds.), Handbook of Qualitative Research ( $2^{\text {nd }}$ ed.), London: Sage Publications, 2000.

Truex, D. P.; Baskerville, R.; and Klein, H. "Growing Systems in Emergent Organizations," Communications of the ACM(42:8), 1999, pp. 117-123.

Truex, D.; Baskerville, R.; and Travis, J. "Amethodical Systems Development: The Deferred Meaning of Systems Development Methods," Accounting, Management \& Information Technology (10), 2000, pp. 53-79.

Walsham, G. "Interpretive Case Sstudies in IS Research: Nature and Method," European Journal of Information Systems (4), 1993, pp. 74-81.

Weick, K. "The Collapse of Sensemaking in Organizations: The Man Gulch Disaster," Administrative Science Quarterly (38), 1993a, pp. 628-652.

Weick, K. "Improvisation as a Mindset for Organizational Analysis," Organization Science (9:5), 1998, pp. 543-555.

Weick, K. "Organizational Redesign as Improvisation," in G. P. Huber and H. W. Glick (Eds.), Organizational Change and Redesign, Oxford: Oxford University Press, 1993b, pp. 346379 . 
Weick, K. "Sensemaking as an Organizational Dimension of Gobal Change," in J. Dutton and D. Cooperrider (Eds.), The Human Dimensions of Global Change, Thousand Oaks, CA: Sage Publications, 1999.

Weick, K. Sensemaking in Organizations, Thousand Oaks, CA: Sage Publications, 1995.

Weick, K. "Sensemaking in Organizations: Small Structures with Large Consequences," in J. K. Murnigham (Ed.), Social Psychology in Organizations: Advances in Theory and Research, Englewood Cliffs, NJ: Prentice-Hall, 1993c.

Weick, K. "Technology as Equivoque: Sensemaking in New Technologies," in P. S. Goodman and L. Sproull (Eds.), Technology and Organizations, San Francisco: Jossey Bass, 1990.

\section{ABOUT THE AUTHORS}

Jørgen P. Bansler is an associate professor at the Technical University of Denmark. His research interests include intranet development, computer-mediated communication, and new organizational forms. Jørgen has a Ph..D. in computer science from the University of Copenhagen, Denmark. He has published in such journals as ACM Transactions on Information Systems, Industrial Relations, Information Technology \& People, Knowledge and Process Management, and Journal of the Association of Information Systems. Jørgen can be reached at bansler@cti.dtu.dk.

Erling C. Havn is an associate professor at the Technical University of Denmark. His research focuses on the ongoing relationship between the development of information technologies and organizing structures, work practices, communication, and control mechanisms. Erling holds a Ph.D. in social sciences from the University of Copenhagen, Denmark. He has published in such journals as Computer Integrated Manufacturing Systems, AI \& Society, International Journal in Human Factors in Manufacturing, Journal of the Association of Information Systems, and Knowledge and Process Management. Erling can be reached at havn@cti.dtu.dk. 